\title{
Export "A" ads are extremely expert, eh?
}

The RJ Reynolds-Macdonald advertising campaign for Export "A" in Canada features solo athletes from various extreme sporting events that they sponsor with the slogan "Go your own way" (fig 1). These ads contain almost all of the elements that its competitors, its US parent, RJ Reynolds, and other transnational firms have found to be so vital and necessary to the commercial success of cigarette brands and industry. Despite the fact that these are sponsorship ads, rather than direct merchandising ads which display the product, they none-the-less dramatically promote brands which are well known to Canadians as cigarettes, and only cigarettes.

\section{The extreme importance of starters}

Cigarette brands enjoy a phenomenally high rate of brand loyalty, consistent with their addictiveness. This brand loyalty is higher than that seen with any other consumer goods. Annual brand switching rates are very low. Those that do switch are not only few in number, but often the most anxious about health risks, and also demonstrably fickle. These traits make switchers a most unattractive type of customer. In contrast, because of the high brand loyalty (year to year retention of customers), starters are highly attractive, as capturing starters builds a solid franchise base that is enjoyed for years. The firms that succeed in capturing starters come to dominate the industry, as best evidenced by Marlboro's history. Put most simply: "To

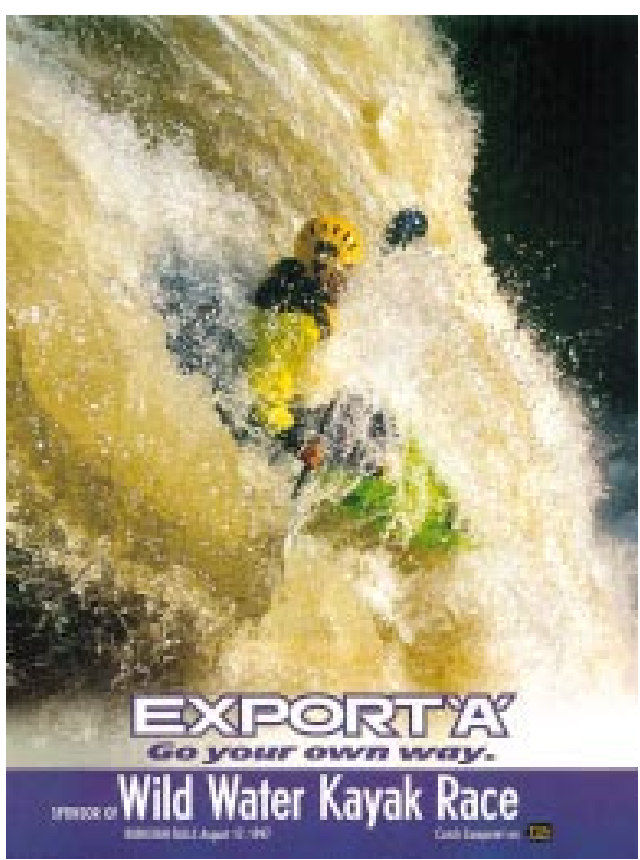

Figure 1 Taking risks in the wild water. succeed in Marlboro Country, you got to corral 'em while they're young and brand 'em while they're young."

The Canadian tobacco industry has long understood this fact of their commercial life, with internal documents saying: "Young smokers represent the major opportunity group for the cigarette industry." Imperial Tobacco, British American Tobacco's Canadian operation, stated in 1988 that: "If the last 10 years have taught us anything, it is that the industry is dominated by the companies who respond most effectively to the needs of younger smokers." 1

During the last two decades, RJRMacdonald's Export " $A$ ” has suffered greatly in its competition with Imperial Tobacco's Player's brand. From 1978 to 1998, Player's market share rose from $14.6 \%$ to $28 \%$, while Export "A"'s fell from $16.7 \%$ to $11.5 \%{ }^{2}$ When Player's modernised its image with ads associating the brand with emergent recreational sports such as hang gliding and wind surfing, Export " $A$ " was left behind with its working class, old fashioned macho, blue collar truck driver image. ${ }^{2}$ No matter how realistically this imagery reflects the social class realities of actual and potential smokers, it fails to capture the aspirations of the young. Like Marlboro in the USA and elsewhere, this success among the young soon translated into a durable dominance of the overall market.

\section{Extremely vital pictures of health}

Cigarette firms learned long ago to use pictures of health in their ads, rather than provide product information or make verbal claims. Imperial Tobacco's statement of philosophies (sic) which prefaced many internal marketing documents expressed a policy to "support the continued social acceptability of smoking through . . . positive lifestyle advertising" (among other activities). Not only does this visual tactic convey healthfulness and promote the social acceptability of cigarettes, but it also deftly finesses the law by avoiding falsifiable verbal claims of fact.

Perhaps most importantly, it also minimises consumers' counter-argumentation-the tendency to talk back inside our heads to verbals claims. Indeed, the prototypical pictures become essentially incredible when made verbal. "Smokers surf" or "Surfers smoke" as verbal copy is far more likely to be dismissed than a picture showing same. Indeed, the very idea of smoking in a white water environment as shown in fig 1 is patently absurd. Visual imagery is apprehended, and the associations of images with cigarettes and brands made, in the very act of perception, without any necessary additional cognitive processing. A 
good picture is worth more than a thousand words, as it takes far less skill and effort and talent for consumers to ingest.

The pictures of health that have characterised cigarette ads for decades have been portrayals of bold and lively behaviour or pure and pristine environments, and often both together. Absent are the realistic, but "dirty" aspects of smoking, like ashtrays and even visible smoke. Instead of any realism, cigarette brands have been frequently associated with sport and recreational activities such as tennis, bicycling, sailing, mountain climbing, hang gliding, wind surfing, and general cavorting outdoors.

\section{Extremely rewarded risk taking}

The Export "A" campaign has pushed the envelope and now encompasses a variety of extreme sports where every competitor gets attention and succeeds precisely because of their willingness to take extreme risks. Within the past year Export " $\mathrm{A}$ " has run advertising calling attention to its sponsorship of extreme ski racing, mountain biking, wild water kayak racing, motorcycle motor cross, and racing on jet skis. In a similar vein, their Canadian competitors Players and Rothmans, like many international brands, sponsor the fastest forms of motor sport racing, and have worked hard to make heroes out of their drivers (fig 2). They enjoy the added commercial benefit of extensive TV and press coverage for both the events and heroes, coverage cultivated by their extensive press relations efforts.

\section{Extremely glamourous and exciting}

The portrayals of the extremely risky sports in recent Export " $A$ " ads have many consistencies, such as the extreme close up on the head of the solo athlete shown, who wears mirrored sunglasses reflecting their sport (fig 3). The sunglasses add several interesting dimensions

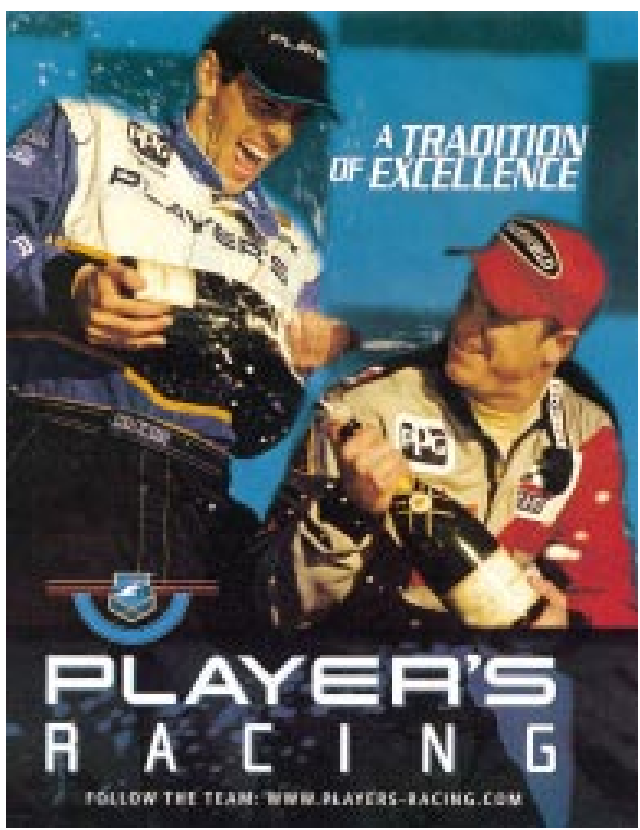

Figure 2 Racing hero enjoys enviable success.

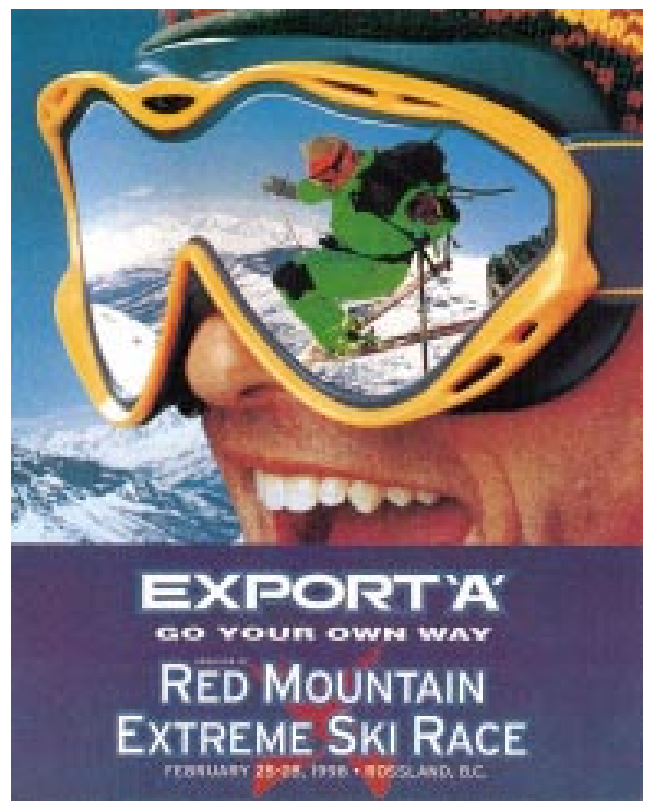

Figure 3 Sport and brand reflecting identity.

to the image. Expensive sport sunglasses are a much prized symbol of status among the young. Their mirrored surfaces add an element of ambiguity and mystery that more readily permits viewers to project themselves into the scene and identify with the image. Perhaps most importantly, digital image manipulation allows the visual to simulate how people are reflected in the mirrored lenses. This resonates with the concerns of the young as to how they will appear to their peers.

Because cigarettes are a visible "badge product", the user's character is displayed every time the branded package is. Corporate documents state: "Very young starter smokers choose Export " $\mathrm{A}$ " because it provides them with an instant badge of masculinity, appeals to their rebellious nature and establishes their position amongst their peers." Elsewhere they described "How We want consumers to view the brand" stating that: "The Export imagery will dimensionalize (sic) the breed of men who are masculine, independent, adventurous and possess the qualities of natural leadership ... Women are attracted to these men because of their youthful virility, independence and spirit of adventure."

\section{Extremely independent and individual}

The industry has long known that the most pressing psychological need of adolescents is their need for independence, autonomy, self reliance-as they seek an adult identity independent of the family cocoon. The brands most successful with teenagers are those that offer adult imagery rich with connotations of independence, freedom from authority, and self reliance. The Marlboro Man epitomises this as he is totally and autonomously free-usually alone and interacting with no one, and always with no parents, no older brothers, no foreman, no bullies, indeed no one at all whose authority must be respected. It seems no accident that there is no sheriff in Marlboro Country. 
In Canada, the Player's campaign was always careful to convey individualism in its visual portrayals of solo surfers, hang gliders, or mountain climbers. Their chosen imagery showed "nobody to interfere, no boss/parents" and used "overtly masculine imagery, targeted at young males ... going through a stage where they are seeking to express their independence and individuality under constant pressure of being accepted by their peers." This appeal to independence and identity was reinforced by the copy writing of the Player's slogan: "A taste you can call your own."1

Since success breeds imitation, the Export "A" slogan also resonates with the adolescent need for independence and identity with similar language: "Go your own way." It seems no accident, indeed it seems essential, that all of the sponsored sports in this Export " $\mathrm{A}$ " campaign are individual sports, and that none are team sports (fig 4). Thus we see skiing, but not ice hockey. We see racing in kayaks or jet skis but not in team events as in dragon boats. Absent are team sports like volleyball, baseball, or soccer, despite their popularity.

\section{Success is extremely likely, but not guaranteed}

No matter how attractive these ads may make smoking appear, their benefit to this brand and this firm is made uncertain for at least two primary reasons. The first lies in the use of pictures of health using emergent contemporary recreations in pure and pristine environments that echos those long used by Player's, even given their current shift of focus to auto racing. Thus, Export " $\mathrm{A}$ " is adopting a "me too" positioning, known to be a difficult task. By imitating and extending that which has been so successful for Player's, they risk falling into the perceptual shadow of Player's brand image, with some viewers confusing their effort

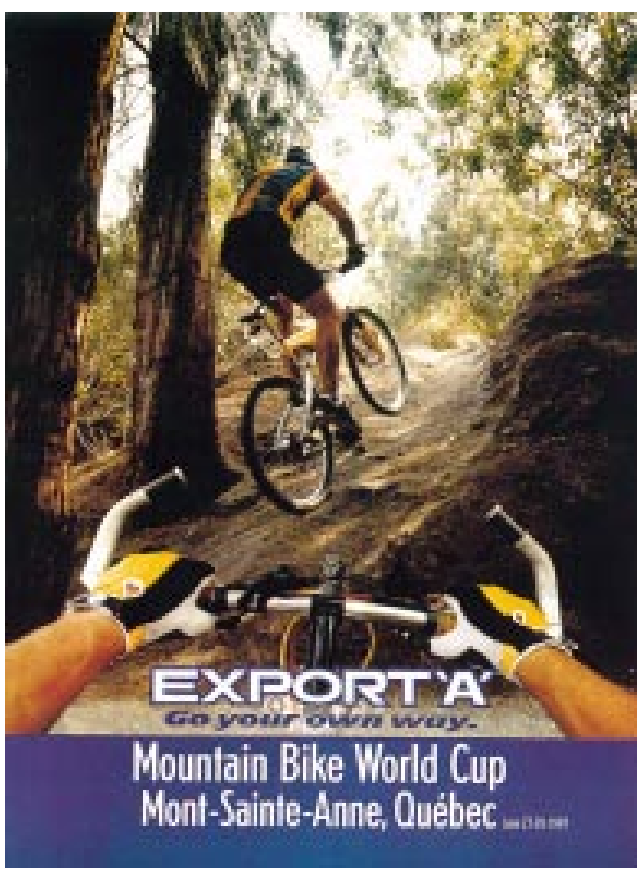

Figure 4 Solo mountain bike racing. with ads for Player's. This risk is increased by the heavy use in its graphics of a shade of blue not very distinct from the well established Player's blue.

The second reason success may be less than hoped is that the ads do not strongly establish a link to the current packaging colours or design, except for the typography of the brand name. The greatest graphic uniqueness is in the dramatic red "X"-symbolic for eXtreme sports and rendered like graffiti painted in a rush with a brush (for example, as in fig 3 ). But neither this extreme " $\mathrm{X}$ " nor the dominant blue are now seen on all Export packaging, which uses various colours as a code to identify strength variations in the product line (for example, "mild" or "light"). Thus, the in-store consumer experience when confronting brands on display would not clearly stimulate recall of the advertising brand imagery by itself, needing the support it gets from in-store posters and displays.

\section{Sponsorship ads still promote cigarette brands}

Positive lifestyle images rehearse and shape perceptions of cigarette brands and smoking, influencing consumer judgments about the popularity of smoking, the healthfulness of smoking, the social approval smokers experience, and the independence and self reliance characteristic of nicotine addicts. ${ }^{3}$ It is relied on by the industry to influence perceptions and attitudes not only of smokers and pre-smokers, but also of their family and friends, the parents and peers of the youth target market that is the future of the industry. ${ }^{1}$

The Export "A" eXtreme campaign uses vivid imagery to command attention. It is placed in paid media far before, far after, and far afield from the nominal events themselves. It is placed on billboards, store window posters and displays, transit advertising, magazines and TV ads to reach a large fraction of the population and to provide persistent reminders. Repetition, often called the soul of persuasion, has the desirable effect of creating what Leo Burnett, the Marlboro ad executive, called "friendly familiarity". Consumers come to trust, and treat as relatively benign, those products and brands that they encounter frequently, as repetition of exposure biases consumers' judgments about the safety of smoking, the popularity of smokers, etc.

For cigarette brands targeting the young, the advertising images portray smokers as independent and enviably adult, athletic, and at home in nature. The Export " $\mathrm{A}$ " campaign does this and more, by associating the brand and cigarette smoking with glamorous contemporary life styles and with highly rewarded risk taking. The Export "A" campaign seems to owe much of its inspiration to its predecessor, the Player's campaign-known to have targeted the young and to have been highly successful at so doing. The Export " $\mathrm{A}$ " striking images attract attention and associate positive lifestyle images with the brand names, logos and other trade mark or graphic signifiers. 
These associations, particularly with repetition, serve to influence the opinions, attitudes, perceptions and beliefs of viewers, whether young or old, smokers or not. It is these factors that bias consumers' judgments and increase the likelihood of smoking.

All of this is totally consistent with the meanings of the words advertising (to turn toward) and promotion (to move forward). These sponsorship ads establish these brand images no less effectively than traditional merchandise advertising. They are, however, different from traditional cigarette ads in two respects: the absence of the fact, well known to Canadian's, that the brands in question refer uniquely to cigarettes, and the absence of any health warning.

Faculty of Commerce,

RICHARD W POLLAY

University of British Columbia

Vancouver, British Columbia

Canada

pollay@commerce.ubc.ca

1 Pollay RW. Targeting youth and concerned smokers: evidence from Canadian tobacco industry documents. Tobacco Control 2000;9136-47.

2 Pollay RW. Export "A" ads are extremely expert, eh? Filter tips: a review of cigarette marketing in Canada. Physicians for a Smoke Free Canada, vol 1, 1998. http://www/smokefree.ca/filtertips_001/Expert-ch.htm

3 US Department of Health and Human Services. Preventing tobacco use among young people. A report of the Surgeon General, 1994. Atlanta, Georgia: Public Health Service, Centers for Disease Control and Prevention, Office on Smoking and Health, 1994. (US Government Printing Office Publication No S/N 017-001-00491-0.)

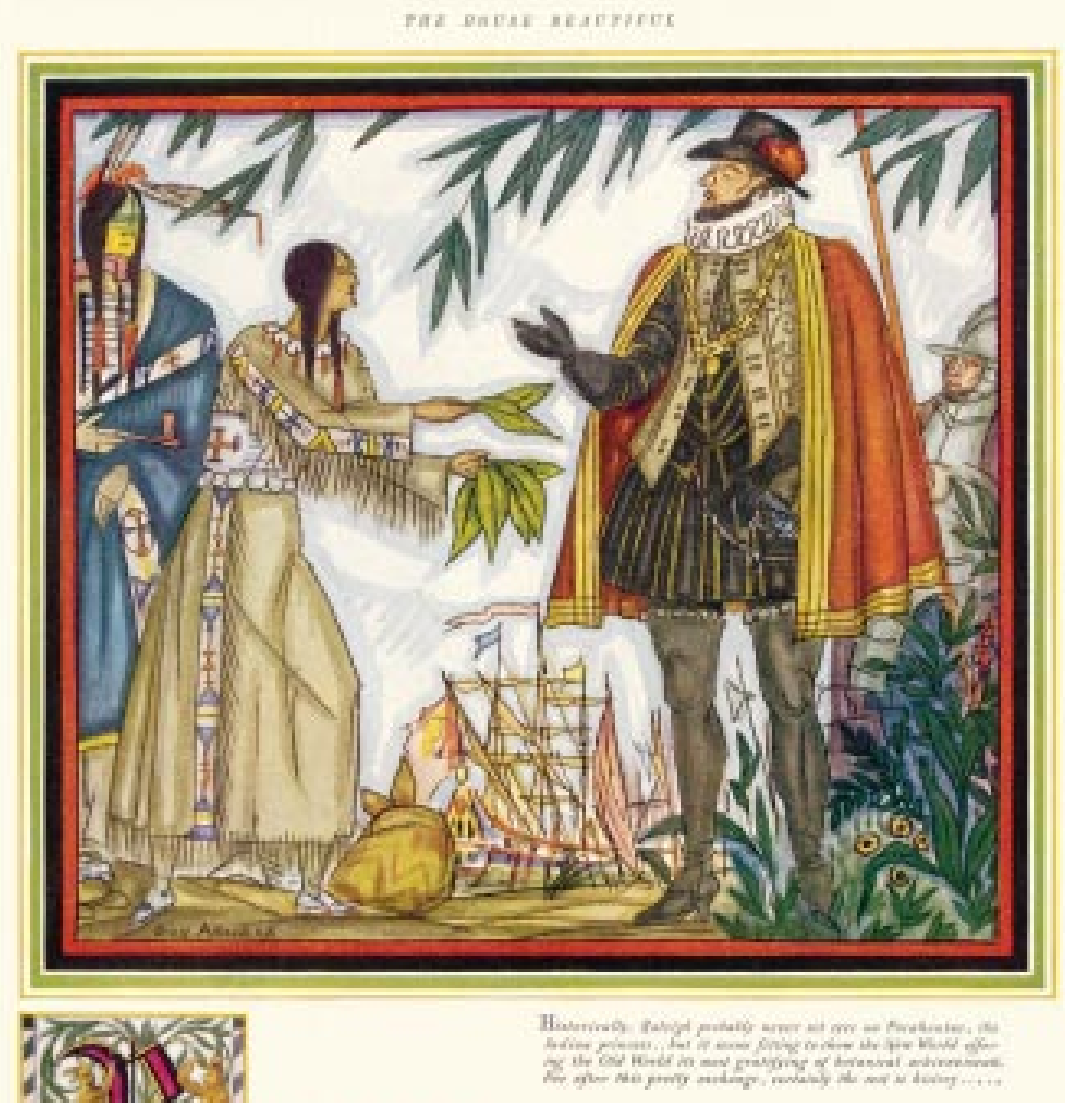

Contributed by Melanie Wakefield.

A LEI GH was the name of a gentlemanadventurer. onso He made tobacco popular. Raleigh is now the name of a new ... a boldly original and an altogether perfect cigarette. It is blended PUFF-by-PUFF DS

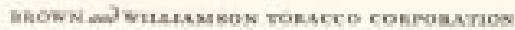
Genith, \&utely
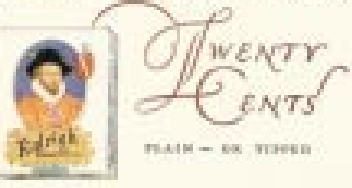